\title{
Análise da incidência de manifestações patológicas em edificações públicas que passaram por processos de reabilitação
}

\author{
R. de A. Garcia Sobrinho ${ }^{1 *}$, L. A. de C. Motta $^{1}$, P. R. C. Guterres ${ }^{1}$ \\ *Contato do autor: renner tt@hotmail.com \\ ${ }^{1}$ PPGEC, Faculdade de Engenharia Civil, Universidade Federal de Uberlândia, Uberlândia, Brasil
}

\begin{abstract}
RESUMO
A reabilitação é uma alternativa sustentável para a construção civil. Porém, verifica-se a existência de poucas literaturas técnicas sobre esta tipologia de obra. Este estudo tem como objetivo levantar e caracterizar manifestações patológicas em edificações públicas que passaram por processos de reabilitação. Foram realizadas inspeções em 8 edificações que passaram por intervenções entre 2018 e 2019. A partir dessas visitas e dos documentos das obras executadas, foram detectados e classificados 4696 pontos de problemas que foram transformados em gráficos para as análises. Detectou-se diversas falhas envolvendo fissurações, umidade e danos aos sistemas. $\mathrm{O}$ estudo evidenciou um estado problemático das obras investigadas, podendo servir de referência para melhorias de processos e base para outros estudos.
\end{abstract}

Palavras-chave: Reabilitação de Edificações; Manifestação Patológica; Obras Públicas; Processos de Reabilitação.

\begin{abstract}
The building rehabilitation is a sustainable alternative for civil construction. However, there are few technical literatures on this type of work. The aim of this study is to survey and characterize pathological manifestations in public buildings that are passed through rehabilitation processes. Were realized Inspections in 8 buildings that underwent interventions between 2018 and 2019. From these visits and from the documents of the works carried out, 4696 problem points were detected and classified, which were transformed into graphs for analysis. Several failures were detected involving cracks, moisture and damage to systems. The study evidenced a problematic state of the investigated buildings, being able to serve as a reference for process improvements and basis for other studies.
\end{abstract}

Key words: Building Rehabilitation; Pathological Manifestation; Public Buildings; Rehabilitation Process.

\section{EL RESUME}


La rehabilitación es una alternativa sostenible a la construcción civil. Sin embargo, existe poca literatura técnica sobre este tipo de trabajos. Este estudio tiene como objetivo plantear y caracterizar manifestaciones patológicas en edificios públicos que han sufrido procesos de rehabilitación. Se realizaron inspecciones en 8 edificios que sufrieron intervenciones entre 2018 y 2019. A partir de estas visitas y de los documentos de las obras realizadas, se detectaron y clasificaron 4696 puntos problemáticos, que fueron transformados en gráficos para su análisis. Se detectaron varias fallas que involucraron grietas, humedad y daños en los sistemas. El estudio evidenció un estado problemático de los trabajos investigados, pudiendo servir de referencia para mejoras de procesos y base para otros estudios.

Palabras clave: Rehabilitación de edificios; Manifestación patológica; Obras Públicas; Procesos de rehabilitación

\section{INTRODUÇÃO}

A construção civil é uma das atividades que mais consomem recursos naturais, tanto na fabricação de seus insumos quanto nos seus processos construtivos. Segundo Torgal e Jagali (2010), "a nível mundial a indústria da construção civil consome mais matérias primas (aproximadamente 3000 $\mathrm{Mt} /$ ano, quase $50 \%$ em massa) que qualquer outra atividade econômica, o que evidencia um setor claramente insustentável". A atividade de construção também gera grandes volumes de resíduos. Segundo Bourscheid e Souza (2010) "o entulho da construção civil tornou-se um grande problema na administração das cidades brasileiras, devido à enorme quantidade (chegando a responder, em alguns casos, por $60 \%$ dos resíduos sólidos urbanos produzidos)". Verifica-se, desse modo, a importância de promover a eficiência do setor da construção, otimizando recursos e minimizando desperdícios, tendo em foco, principalmente, a sustentabilidade (Sáez et. al, 2019; Qualharini, 2017; Agopyan e John, 2011).

De acordo com Mateus (2009):

Para que um edifício seja sustentável é necessário que durante o seu ciclo de vida se respeitem, entre outras, as seguintes prioridades: otimizar o potencial do terreno; preservar a identidade cultural regional; minimizar o consumo de energia; proteger e preservar os recursos de água; utilizar materiais e produtos de construção eco-eficientes; manter um ambiente interior saudável e confortável; otimizar as práticas de utilização e de manutenção; e reduzir os custos de ciclo de vida.

Ou seja, verifica-se que a sustentabilidade na construção civil deve abranger todos os processos das etapas de construção e de utilização. Sendo assim, as edificações não podem ser vistas como produtos descartáveis, que serão inutilizados ao fim de sua vida útil ou se apresentarem problemas e defeitos. Um conceito que está sendo aplicado à sustentabilidade na construção, que envolve a solução de problemas das edificações já existentes, é a reabilitação de edifícios.

No processo de reabilitação de um imóvel, geralmente, aproveita-se os sistemas já construídos e evita-se demolições minimizando, assim, o consumo de materiais e a geração de resíduos. Desse modo, observa-se a relevância da prática de reabilitação de edificação para minimizar os prejuízos ambientais causados pela construção civil e verifica-se a possibilidade de enquadrar esse processo na definição de sustentabilidade proposta por Bruntland (1987), onde o desenvolvimento sustentável é aquele que "permite satisfazer as necessidades do presente sem comprometer as possibilidades das gerações futuras satisfazerem as suas". (Almeida et al., 2017; Batista, 2014; Thomsen e van, 2009; Mikhailova, 2004).

As obras de reabilitação têm características próprias que as diferenciam das obras de construção nova. Elas possuem particularidades quanto aos seus custos, planejamento, capacitação de mão de obra, projetos entre outros. A reabilitação nem sempre é a alternativa mais econômica em relação 
à demolição e à execução de edifícios novos sendo, muitas vezes, não utilizada mesmo com seus benefícios ambientais (Rodríguez et. al, 2017; Brás, 2015; Martins, 2011; Tuppurainen, 1990).

Segundo Miragaia (2011) "reabilitar é muito mais complicado do que construir a partir do zero; pois implica a utilização de materiais e tecnologias diferentes das habitualmente utilizadas em construção nova".

De acordo com Jesus (2008):

[...] as particularidades relativas à produção de reabilitação de edifícios não têm sido objeto de estudo sistêmico. Há expressivo desconhecimento sobre a dinâmica de produção deste tipo de empreendimento, o que tem resultado, sobretudo, em obras cujos custos usualmente extrapolam as estimativas iniciais.

Para Correia 2009 “Apesar da extensa bibliografia existente, constata-se a inexistência de estudos concretos sobre a duração das diferentes etapas, os custos de construção do processo de reabilitação e a própria metodologia de intervenção". Deste modo, verifica-se a necessidade de estudos que caracterizem esse tipo de obra, levantando seus principais problemas e propondo possíveis soluções ou medidas paliativas.

Os edifícios que passam por reabilitação, na maioria das vezes, já estão com sua vida útil em operação, portanto, seus sistemas já estão em processo de desgaste. Além disso, vários outros fatores podem influenciar no surgimento de problemas no imóvel gerando, assim, manifestações patológicas (Possan e Demoliner, 2013; Qualharini et al., 2001).

O estudo de patologia é uma ferramenta que traz bons resultados retroalimentando o processo construtivo e solucionando, de maneira eficiente, os problemas. Dentre os vários tipos de estudo envolvendo patologias tem-se a caracterização de manifestações patológicas (Villa e Ornstein, 2013; Thomaz, 2001).

Verificam-se poucos estudos de pós-obra e caracterização de anomalias em edificações que passaram por processos de reabilitação. A questão é que os problemas formados após a execução desta tipologia de obra poderiam ter sido solucionados ou evitados no próprio procedimento. Sendo assim, uma reabilitação ineficiente vai demandar de outra intervenção em menor prazo de tempo. As obras públicas costumam apresentar, constantemente, irregularidades como o aumento de orçamento e/ou aumento de prazos. Dessa maneira, existe a possibilidade de que os processos de reabilitação nessas obras sejam feitos de maneira ineficiente, negligenciando fatores importantes ou não sendo executados plenamente. O setor de construção gasta muitos recursos públicos, é inconcebível que obras reabilitadas necessitem de mais recursos e novas intervenção devido a procedimentos inadequados (Santos et al., 2015; Campelo e Cavalcante, 2013).

Sendo assim, observa-se dois pontos relevantes que necessitam de maiores investigações quanto aos seus procedimentos e aplicações sendo eles: as obras de reabilitação e as obras públicas. Desse modo, o presente trabalho tem como objetivo estudar e levantar manifestações patológicas em edificações públicas que passaram por processos de reabilitação, por meio de análises qualitativas e descritivas caracterizando, assim, os principais problemas encontrados.

\section{PROCEDIMENTO}

Para a investigação, foram realizados levantamentos das manifestações patológicas em edificações públicas, por meio de inspeções. $\mathrm{O}$ estudo foi realizado na cidade de Uberlândia, localizada no estado de Minas Gerais, Brasil.

As visitas foram realizadas em 8 escolas que passaram por processos de reabilitação entre 2018 e 2019. As inspeções ocorreram no período de 11 a 18 de dezembro de 2019. Foi analisada, também, a documentação gerada no processo de licitação das obras estudadas por meio de documentos como: projetos arquitetônicos e complementares, manuais descritivos, orçamentos e cronogramas físico-financeiros. 
Cada manifestação patologica encontrada foi catalogada e classificada. Entende-se como manifestação patológica, para esse trabalho, qualquer problema na edificação que possa ser identificado por meio da análise sensorial.

As anomalias detectadas foram catalogadas em grupos de manifestações patológicas. Para agrupar os problemas, seguiu-se as linhas estabelecidas por Ioshimoto (1988), Azevedo (2008) e Carraro e Dias (2014), com algumas adaptações que foram necessárias para abranger todos os problemas encontrados no estudo. Adicionou-se alguns agrupamentos baseados nos estudos de Brito et al. (2011) e de Cupertino e Branstetter (2015). Os grupos de manifestações patológicas podem ser observados na Tabela 1.

Tabela 1. Agrupamentos das manifestações patológicas

\begin{tabular}{|c|c|}
\hline Agrupamento de manifestação & Critérios de classificação \\
\hline Fissurações & $\begin{array}{c}\text { Todos os problemas relativos a fissuras, trincas, } \\
\text { rachaduras e fendas, de todas as formas e } \\
\text { configurações; }\end{array}$ \\
\hline Umidade & $\begin{array}{l}\text { Qualquer problema relacionado a presença de } \\
\text { umidade na edificação; }\end{array}$ \\
\hline Perda de material & $\begin{array}{l}\text { Situações em que ocorre perda de massa em } \\
\text { elementos estruturais, vedações ou pisos. Estão } \\
\text { incluídos nesta categoria desplacamento de } \\
\text { revestimento, de pintura, esboroamentos, perdas } \\
\text { volumétricas, buracos, entre outros. }\end{array}$ \\
\hline Irregularidade nos acabamentos & $\begin{array}{l}\text { Qualquer deficiência na parte superficial do } \\
\text { acabamento da edificação, relativa ao seu } \\
\text { desempenho visual e/ou sua estruturação. Estão } \\
\text { incluídos nesses problemas desnivelamentos } \\
\text { visíveis em revestimentos, abaulamento, variação } \\
\text { de textura indesejada, pintura irregular, manchas } \\
\text { de tinta, entre outros. Não estão incluídas machas } \\
\text { relacionadas diretamente com a umidade. }\end{array}$ \\
\hline Problemas nas instalações prediais & $\begin{array}{c}\text { Foram consideradas manifestações nas instalações } \\
\text { prediais os problemas que apresentavam prejuízos } \\
\text { a funcionalidade dos seus sistemas ou os danos } \\
\text { em seus componentes. }\end{array}$ \\
\hline Problemas nas esquadrias & $\begin{array}{l}\text { Estão classificados nesta categoria defeitos que } \\
\text { prejudiquem a funcionalidade das esquadria e } \\
\text { danos causados aos seus componentes. } \\
\text { Independente de qual for a causa, os prejuízos a } \\
\text { estrutura física da esquadria estão enquadrados } \\
\text { nesse grupo. }\end{array}$ \\
\hline
\end{tabular}

Além dos agrupamentos de manifestações, cada anomalia detectada também foi atribuída a um problema nos procedimentos de reabilitação. As falhas decorrentes do processo de intervenção podem ser vistas na Tabela 2. O enquadramento de cada manifestação patológica nesses problemas foi realizado a partir de uma análise global relacionando o problema, os levantamentos obtidos nas inspeções e a documentação produzida para as obras das edificações investigadas.

Tabela 2. Tipos de falhas relacionados ao processo de reabilitação 


\begin{tabular}{|l|l|}
\hline Problemas gerados na intervenção & $\begin{array}{l}\text { Aqueles que foram incorporados na edificação } \\
\text { durante o processo de reabilitação }\end{array}$ \\
\hline Solução não proposta & $\begin{array}{l}\text { São as manifestações que já existiam antes da } \\
\text { intervenção e não foram tratadas por não terem } \\
\text { nenhuma solução especificada no projeto }\end{array}$ \\
\hline Solução insuficiente & $\begin{array}{l}\text { Acontece quando a medida de recuperação } \\
\text { proposta não é suficiente para solucionar os } \\
\text { problemas que deveria }\end{array}$ \\
\hline Problema gerado após a intervenção & $\begin{array}{l}\text { São referentes às manifestações que foram } \\
\text { introduzidas na edificação após o processo de } \\
\text { reabilitação concluído }\end{array}$ \\
\hline Solução executada inadequadamente & $\begin{array}{l}\text { São referentes às propostas de reabilitação que } \\
\text { foram executadas incorretamente resultando no } \\
\text { agravamento do quadro ou reincidência dos } \\
\text { problemas }\end{array}$ \\
\hline Solução não executada & $\begin{array}{l}\text { Ocorre quando a solução definida na proposta da } \\
\text { reabilitação não foi realizada }\end{array}$ \\
\hline
\end{tabular}

Após a catalogação e classificação das manifestações, os dados obtidos foram transformados em gráficos para visualização do cenário estudado. A estatística utilizada foi do tipo descritiva, ela teve como foco demonstrar, exclusivamente, os dados da investigação.

Foram obtidas na inspeção 4481 imagens que possuíam, no total, 4696, pontos com manifestações patológicas, de acordo com as classificações estabelecidas para o estudo. Esses dados foram transforados em dois gráficos:

- Um deles demonstra a porcentagem da incidência de cada agrupamento de manifestação patológica, de acordo com o total de problemas encontrados, em todas as edificações estudadas; - O outro mostra a porcentagem de cada problema, relativo aos processos de reabilitação, dentro de cada agrupamento de manifestações patológicas.

A partir dos gráficos obtidos são feitas discussões, apontamentos e análises qualitativas em relação aos resultados.

\section{RESULTADOS}

As porcentagens relativas a cada agrupamentos das manifestações patológicas, em relação a todos problemas encontrados nas edificações, podem ser vistas no Figura 1.

Os principais problemas encontrados estão associados com as fissurações (42\%); seguidos de irregularidades no acabamento $(26 \%)$ e perda de material $(19 \%)$. As umidades representaram $8 \%$ no total das manifestações e os problemas em esquadrias e em instalações prediais 3\% cada. A relação entre as porcentagens dos problemas relacionados com a reabilitação em cada agrupamento de manifestações, pode ser observada no Figura 2.

Observou-se que o maior problema relativo às fissurações é a falta de proposições de tratamentos destas nos projetos de reabilitação. Este tipo de manifestação patológica representa $42 \%$ do total de deficiências encontradas nos edifícios estudados, isso pode indicar que as fissurações são um dos defeitos mais negligenciado no momento de propor soluções para reabilitar um edifício. 


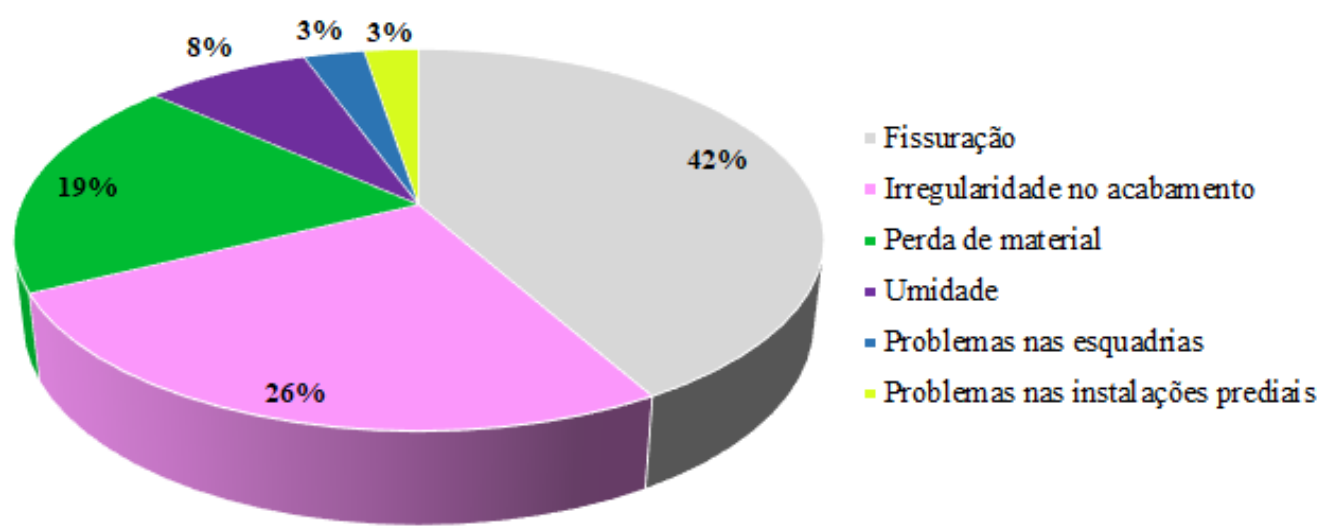

Figura 1. Manifestações patológicas em obras de reabilitação

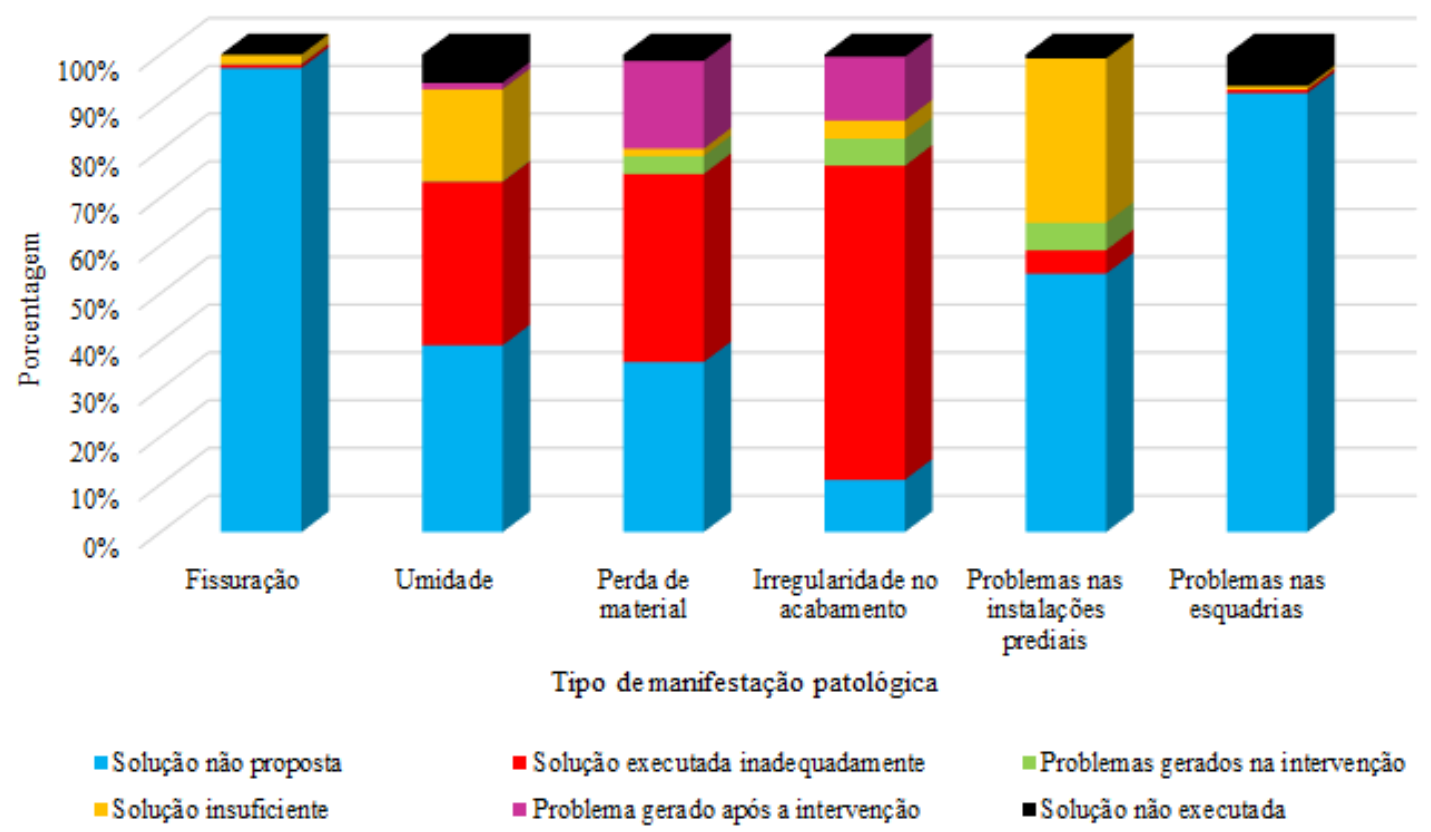

Figura 2. Relação de manifestações por problemas de intervenção

Foi possível observar diversas modalidades de problemas referentes as fissuras. Um exemplo desta situação é o péssimo estado de conservação que se encontram algumas juntas de dilatação. Em alguns casos, elas contêm infiltração, o que pode gerar prejuízos à estrutura. Esses problemas podem ser visualizados na Figura 3.
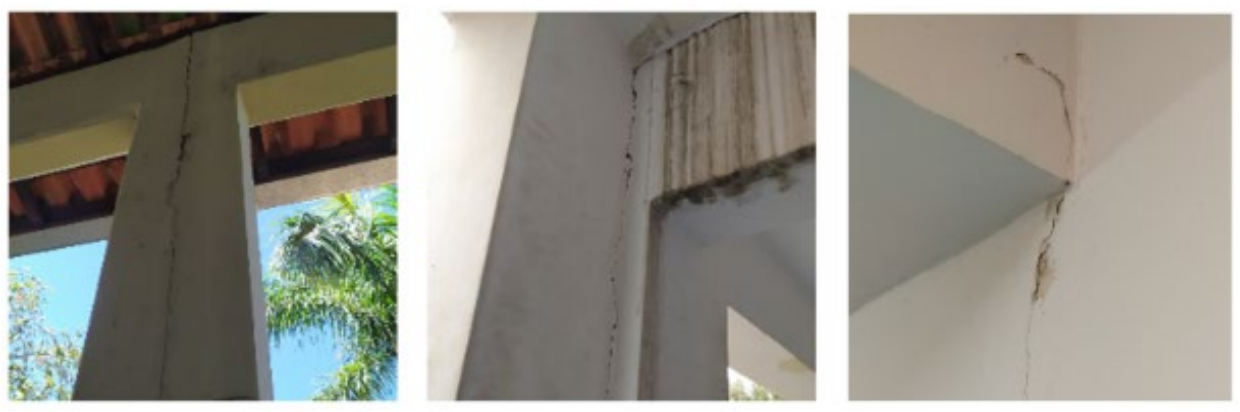

Figura 3. Juntas de dilatação com fissuras 
Foram encontradas, também, muitas fissuras, trincas e rachaduras em pontos de concentração de tensões em esquadrias, provavelmente por inexistência e/ou deficiência de vergas e contravergas, essa situação pode ser observada na Figura 4.
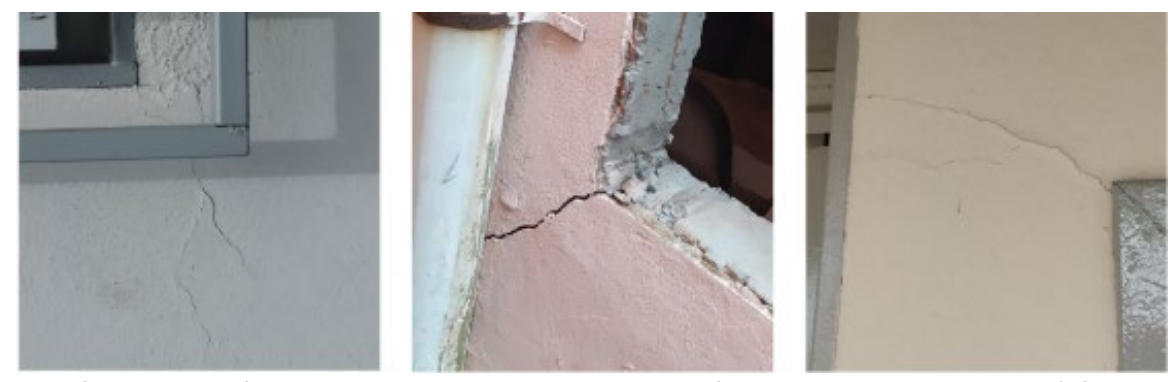

Figura 4. Fissuração por concentração de tensões nas esquadrias

Alguns tratamentos de fissuras ativas são propostos e/ou executados de maneira inadequada; como a realização somente do emassamento, por exemplo, para recuperação do problema. Como consequência, o defeito volta a ocorrer. Essa situação pode ser verificada na Figura 5.

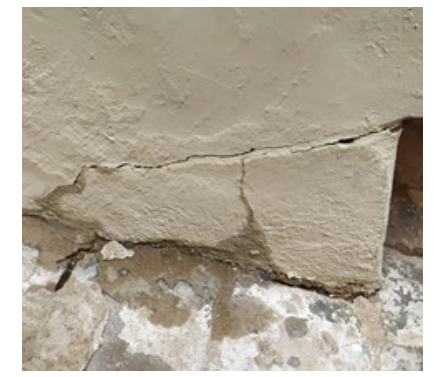

Figura 5. Reincidência de trinca ativa

No caso da umidade, ela é o quarto item com maior representatividade dentro dos agrupamentos de manifestações patológicas, com $8 \%$ de relevância. Porém, verificou-se que mesmo sendo quantitativamente menor, esse tipo de problema influencia diretamente na salubridade e durabilidade da edificação.

Observando a Figura 2, as soluções que foram propostas de maneira insuficiente para o tratamento do problema são mais de $30 \%$ das causas relativas à umidade. Maioria dessas propostas inadequadas estão relacionadas com intervenções em coberturas sem detalhamento, proposições essas que só destinaram uma porcentagem da área do telhado para substituição sem avaliar de fato qual era a origem da umidade.

Algumas intervenções para solucionar problemas, relativos à umidade, foram especificadas adequadamente no projeto, porém, mesmo após a reabilitação, os problemas ainda continuam ou podem até ter se agravado. Esses itens foram definidos como soluções executadas inadequadamente.

Uma edificação, que tinha um dos projetos de intervenção no telhado mais detalhado, apresentou um estado de degradação avançada em relação a umidade. Isso pode indicar problemas relativos aos processos de execução. Na Figura 6 é possível verificar alguns problemas de umidade, desta edificação, devido a intervenção em seu telhado. 

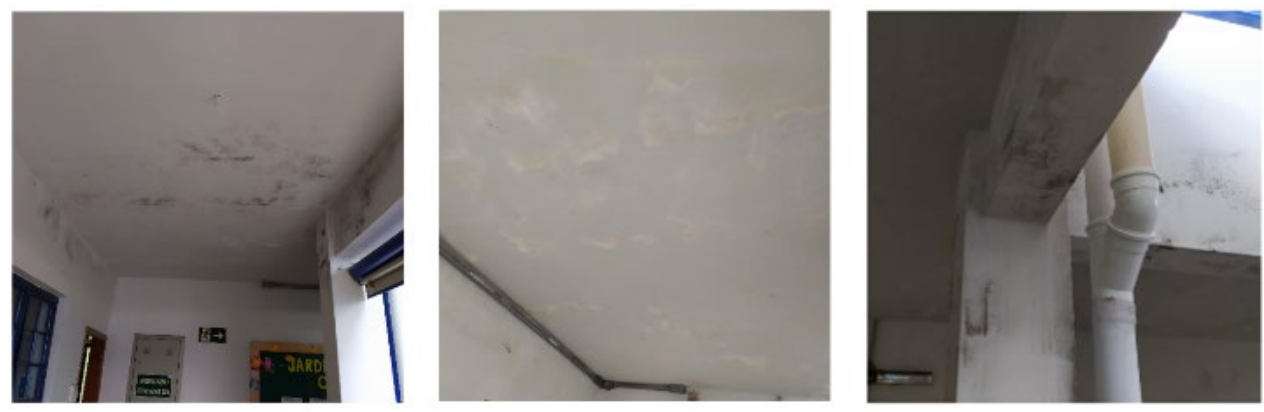

Figura 6. Infiltração por reabilitação inadequada em cobertura

Na Figura 7 é possível averiguar a gravidade que problemas de umidade podem gerar para a salubridade da edificação, onde se tem, como consequência, a presença de fungos em ambientes fechados.
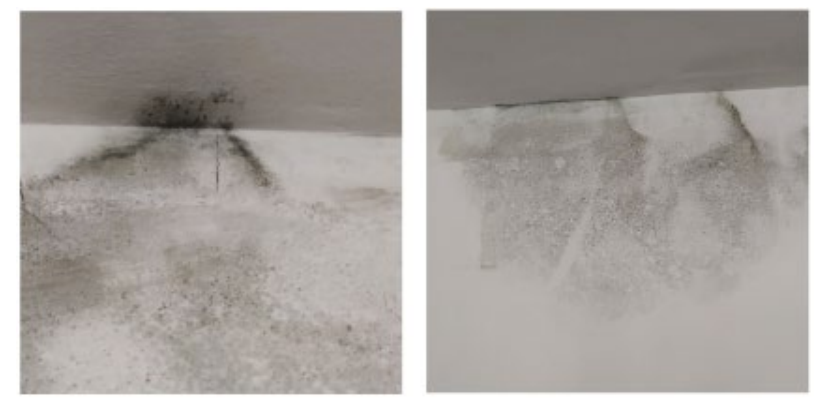

Figura 7. Fungos gerados pela umidade

No caso de não ser proposto um tratamento para a umidade, é adequado escolher materiais que tenham desempenho melhor nessas condições. Esta questão pode ser vista na Figura 8, onde o emprego de pintura acrílica dificultou a ventilação do revestimento, aumentando a concentração da umidade e agravando, assim, problemas como: empolamento, eflorescências, criptoflorescências e perda de revestimento.
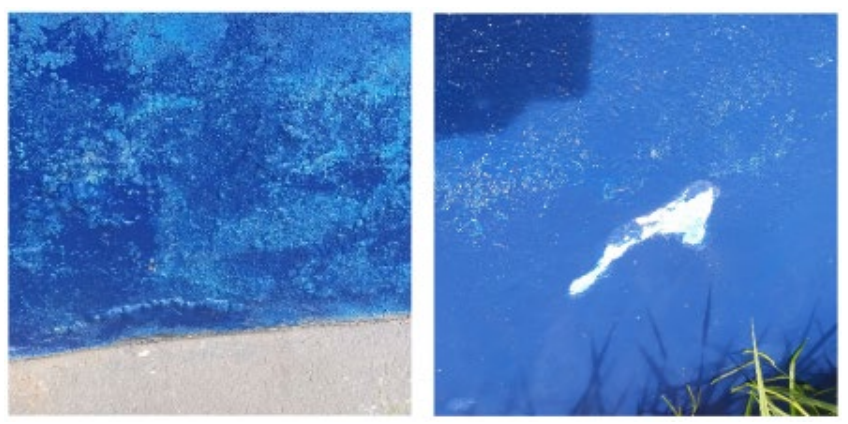

Figura 8. Problemas com umidade ascensional

Quando se observa os problemas relacionados com o agrupamento de manifestações de perda de material, verifica-se que a maior parte desses estão relacionados a soluções que não foram executadas adequadamente. A perda de aderência de pintura foi um dos itens que foram relacionados a esse grupo. Essa falha técnica ocorreu na maioria dos casos observados, por causa de uma preparação inadequada da superfície que foi pintada, como pode ser observado na Figura 9. Verificou-se que, geralmente, a pintura antiga não é lixada e removida adequadamente, mesmo quando é especificado no projeto básico esta atividade de apresto. Isso resulta em degradação precoce dos sistemas de pintura, mesmo após pouco tempo da execução da reabilitação. 

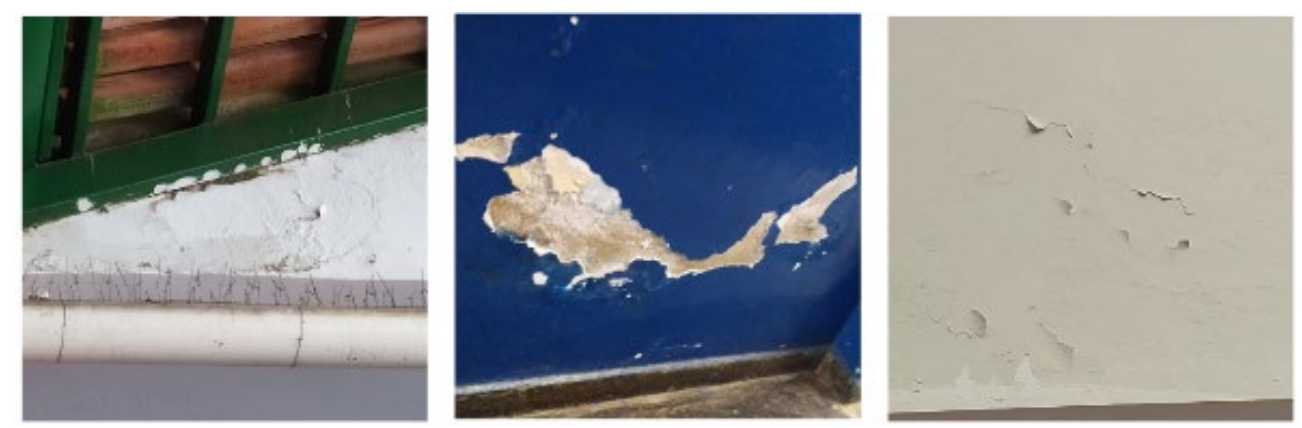

Figura 9. Desplacamento de pintura por preparação inadequada da base

Alguns dos problemas mais significativos, em relação a perda de material, foram os que surgiram após a reabilitação realizada. Muitos desses foram decorrentes do mau uso e operação nos espaços. Observou-se muitos esboroamentos de revestimento resultantes de impactos ocorridos na movimentação de equipamentos na edificação. Alguns destes casos podem ser observados na Figura 10.
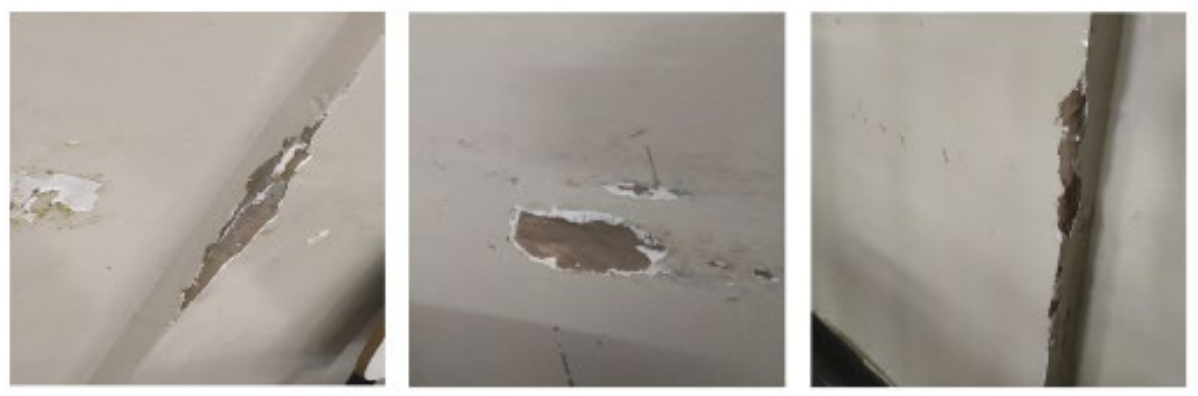

Figura 10. Perda de material por impacto de equipamentos

Quanto à parcela relativa às soluções não propostas, que foi mais de $30 \%$ dos problemas de perda de material, verificou-se que muitos desplacamentos e esboroamentos não tiveram recomendações de tratamento em projeto. Foram encontrados casos com desplacamento em regiões externas da alvenaria que resultaram em infiltrações no ambiente interno. Foi comum encontrar revestimento cerâmico desplacando ou danificados em ambientes como cozinha e banheiros. Na Figura 11, é possível observar alguns casos de perda de material que não tiveram soluções propostas em projeto.
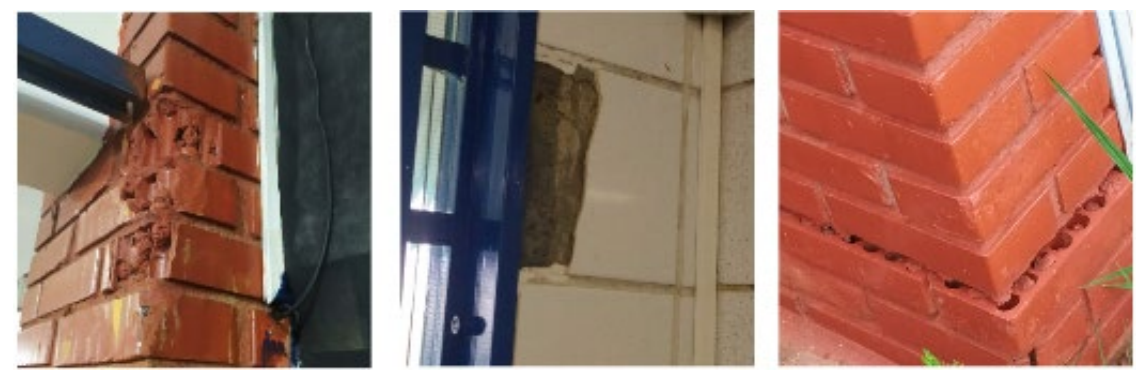

Figura 11. Perda de material que não foi proposto solução

Dentre as situações encontradas, destacou-se uma onde foi proposto a substituição das placas cerâmicas que estavam desplacando, mas, provavelmente não foi realizado uma investigação profunda da estabilidade dos demais componentes do revestimento. Como resultado, a área destinada a recuperação foi tratada, porém, outras regiões vieram a sofrer desplacamento após a intervenção. Esse caso pode ser observado na Figura 12. 


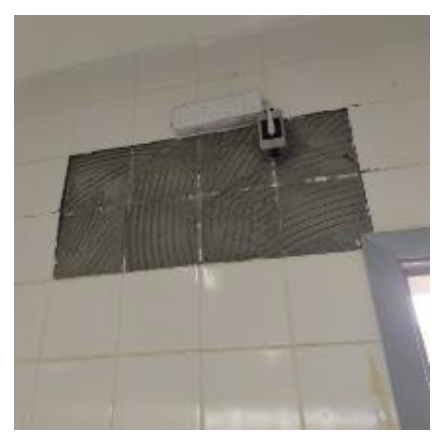

Figura 12. Desplacamento de revestimento cerâmico após a intervenção

Em relação ao grupo de manifestações de irregularidades nos acabamentos, os problemas mais significativos estão relacionados com a execução inadequada dos processos de reabilitação. No caso da pintura, já foi levantado, neste texto, sobre a consequência da preparação inadequada da base para execução da pintura nova, nesse caso, a principal causa foi um processo mau feito de lixamento e remoção de tinta na perda de material, entretanto, não é a única consequência que foi observada. Alguns elementos deveriam ter sido retirados no processo de preparação da base para pintura e não foram, desse modo, gerou-se inadequações no acabamento final. Foram encontradas gomas de mascar, fitas adesivas, restos de papeis aderidos a tinta antigas, entre outros resíduos que não foram removidos. A pintura foi, nesses casos, executada sobre os mesmos. Na Figura 13 é possível ver as situações descritas.
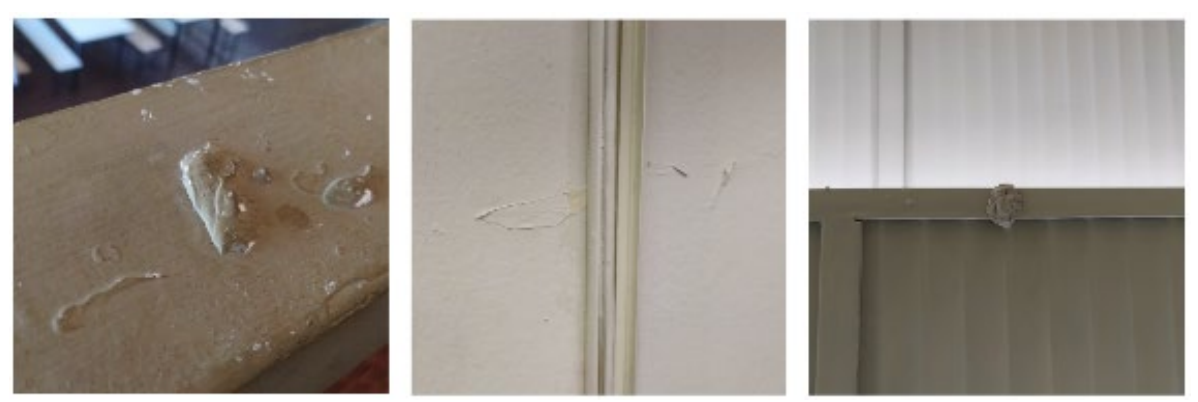

Figura 13. Materiais não removidos na base da pintura

Foram detectadas regiões que não passaram pela limpeza adequada para o processo de pintura, como pode ser visto na esquadria da Figura 14. A janela em questão estava suja de poeira na execução do acabamento; sendo assim, a sujidade incorporou ao pigmento não sendo mais possível remove-la da esquadria.

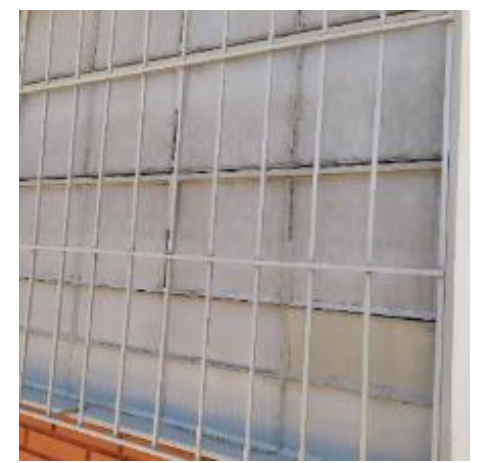

Figura 14. Esquadria com pintura sobre sujidade 
Outro problema, em relação aos procedimentos de execução responsáveis por irregularidades nos acabamentos, foi a pintura, principalmente com aplicações de spray, em regiões onde as demais finalizações já estavam prontas, sem a realização da proteção adequada destes, ocasionando, assim, em manchas de tinta. Esta questão pode ser ver verificada na Figura 15.
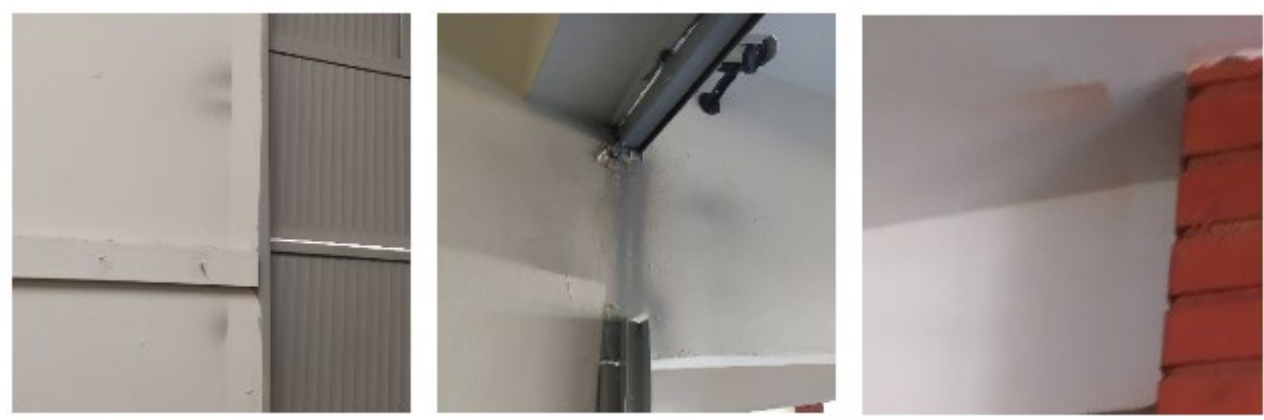

Figura 15. Mancha de tinta por não proteção adequada dos outros acabamentos

Quanto às soluções que não foram propostas ou foram definidas de maneira insuficiente nos acabamentos, ambas estão relacionadas, principalmente, com deficiências na especificação no projeto para regularização dos acabamentos; como, por exemplo, a ausência de emassamento ou a proposição deste em quantidades inferiores às necessárias. Na Figura 16 é possível ver a situação exemplificada.
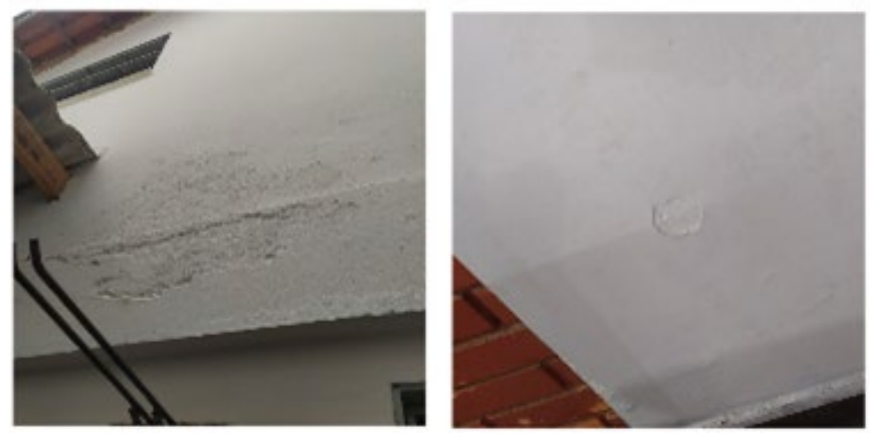

Figura 16. Irregularidade no acabamento por falta de material de regularização

Os principais problemas detectados que estão relacionados às instalações prediais foram os defeitos que não tiveram solução proposta em projeto. Isto pode ser visto, principalmente, nas instalações hidráulicas. As manifestações encontradas neste tipo de instalação, na maioria das vezes, não tinham especificações de solução nas propostas de reabilitação. Alguns problemas relativos a este tipo de instalação podem ser vistos na Figura 17.
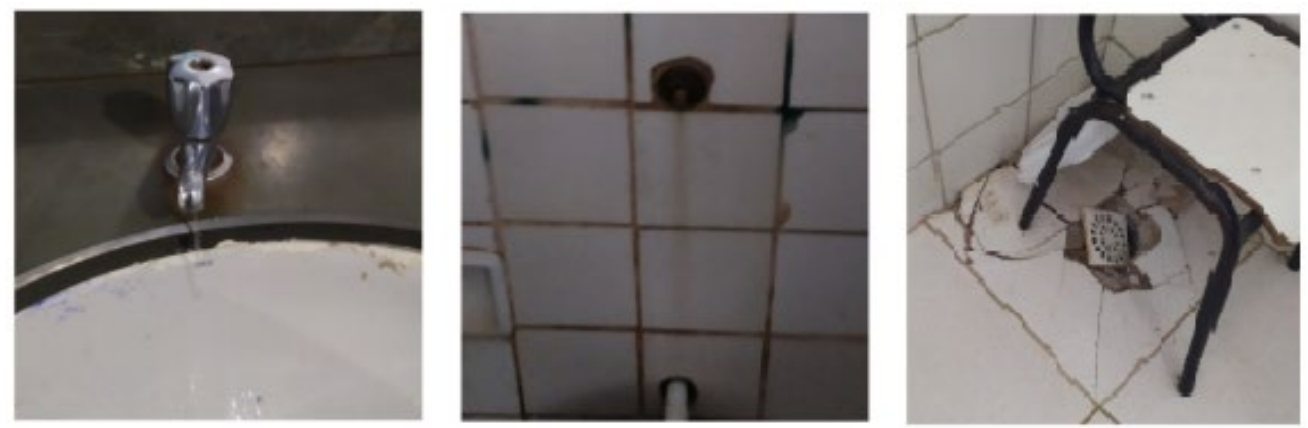

Figura 17. Problemas nas instalações hidráulicas que não tiveram soluções propostas 
Em relação às soluções que foram insuficientes, estas estão mais associadas às instalações elétricas. Nos projetos investigados, a maioria deles sugeriram uma porcentagem do valor da obra para reparos de problemas em sistemas elétricos, que não foram possíveis de serem verificados nas vistorias, sem detalhamentos ou uma análise mais adequada das intervenções necessárias nos sistemas elétricos. Observou-se que esta abordagem não foi adequada para solucionar os problemas relativos às instalações. Algumas manifestações relacionadas às instalações elétricas prediais podem ser observadas na Figura 18.
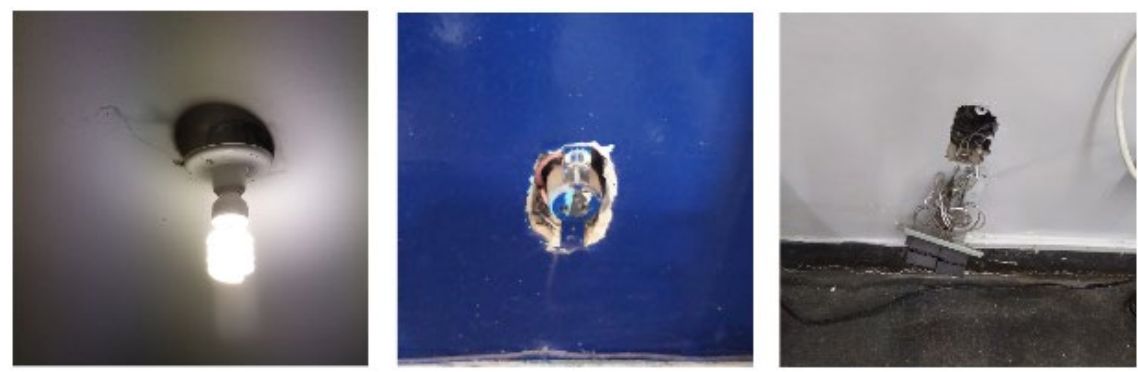

Figura 18. Problemas nas instalações elétricas por soluções insuficientes

Quanto às esquadrias, as intervenções realizadas neste tipo de elemento, na maioria das vezes, são destinadas a regularização de normas de físcalização, como, por exemplo, aumentar uma janela na sala de gêneros para atender as exigências da vigilância sanitária. Detectou-se que algumas esquadrias com defeitos, como corrosão, não foram destinadas à recuperação, como pode ser verificado na Figura 19.
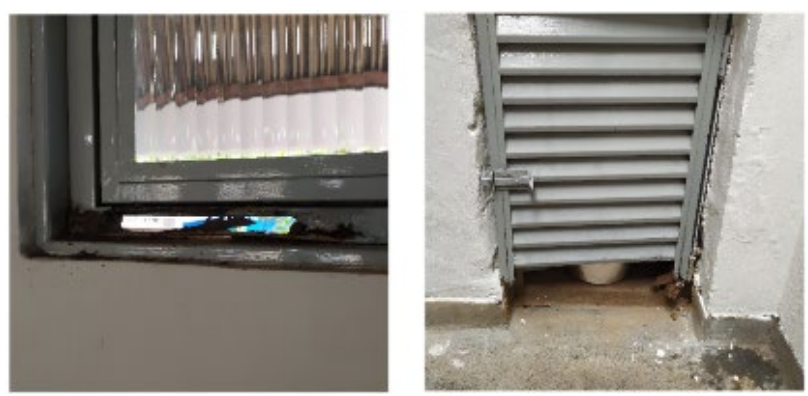

Figura 19. Esquadrias com defeitos de corrosão

Verificou-se que alguns projetos tinham intervenções referentes à substituição de portas e janelas; porém, estes não costumam abranger todos os problemas da edificação e nem sempre são executados. Outros pontos encontrados foram problemas nos componentes das esquadrias como: maçanetas, portais que possuem defeitos, vidros quebrados, entre outros. Esses defeitos podem ser observados na Figura 20.
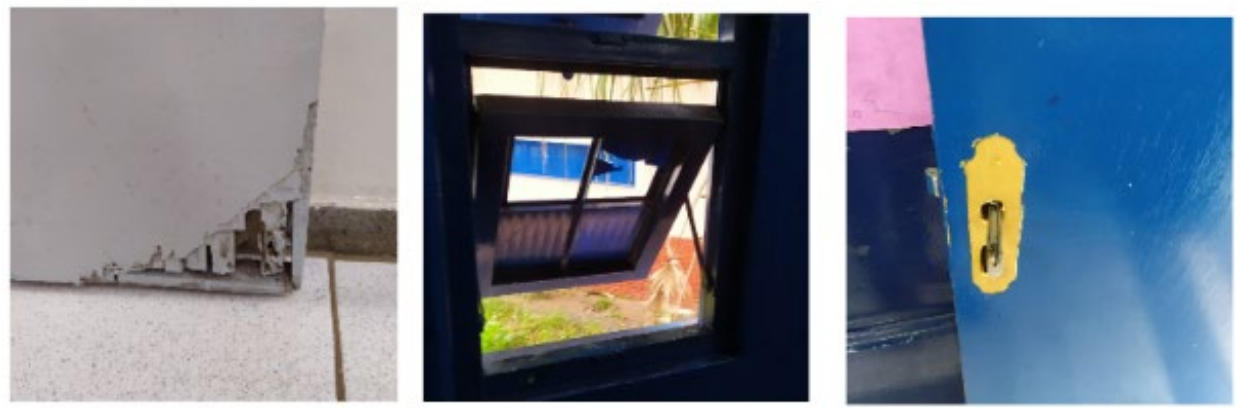

Figura 20. Problemas em esquadrias não solucionados 
Desse modo, foi possível verificar várias ineficiências nos processos de reabilitação estudados quanto as proposições de soluções para as manifestações patológicas nas edificações investigadas. Os problemas que não são apontadas soluções nos projetos são os mais relevantes dentre as possíveis falhas nas reabilitações e tem maior incidência nos agrupamentos de fissurações, instalações prediais e esquadrias.

A pintura se mostrou um dos sistemas mais prejudicados. Observou-se que grande parte dos problemas de irregularidades no acabamento e de perda de materiais estão relacionados a ela. $\mathrm{O}$ processo de preparo inadequado da base para execução da pintura foi observado em vários pontos investigados, mesmo quando se tinha orçamento para essas atividades.

Os problemas relativos a execução inadequada foi o segundo mais relevante. As irregularidades no acabamento são as que mais tem problemas relativos a execução malfeita, seguida da umidade e da perda de material.

As fissurações e perda de materiais em elementos estruturais são prejudiciais para a vida útil da edificação por causa da perda de cobrimento e facilitação da entrada de agentes deletérios no concreto. A umidade também pode acelerar a degradação das construções e causar situações de insalubridade como o caso da proliferação de fungos detectada nas inspeções. Revestimento desplacando, como foi observado na investigação, é um risco adicional à segurança dos usuários.

Desse modo é possível verificar vários problemas em todas as fases da edificação que não estão sendo solucionados nos processos de reabilitação. Desse modo são geradas obras ineficientes e as edificações já apresentam problemas pouco tempo após a intervenção.

\section{CONCLUSÕES}

Tendo em vista os problemas levantados, observou-se que os processos de reabilitação estudados não foram eficientes para recuperar a edificação, principalmente em seus problemas mais graves ou mais urgentes, e que parte do que é proposto veem sendo executado de forma inadequada, como é o caso da pintura.

Estes pontos podem evidenciar deficiências relevantes em procedimentos de reabilitação de obras públicas. Em relação as manifestações, nem todos os problemas encontrados necessitam ser recuperados, algumas fissurações e irregularidades de acabamentos, por exemplo, produzem danos exclusivamente estéticos. Porém, alguns defeitos que estão relacionados diretamente com a salubridade da edificação, a segurança dos seus usuários e durabilidade foram detectados, mesmo com as edificações tendo passado por reabilitação. Esses itens deveriam ser prioridade sobre os demais na proposição de soluções e também ter mais rigor técnico em sua fiscalização e execução. A estanqueidade da edificação se mostrou um dos itens mais problemáticos relacionado a durabilidade do ambiente construído, pois, foi possível observar que uma intervenção mal realizada na cobertura, por exemplo, pode gerar um processo acelerado de degradação.

Sendo assim, foi possível observar diversas ineficiências nos processos de reabilitação que foram aplicados nas edificações públicas investigadas. Deste modo, o presente trabalho pode servir de fonte de informação para melhoria dessas tipologias de obras. Foi possível, também, produzir conteúdo e caracterização relacionado a tecnologia de reabilitação de edifícios que podem orientar novas investigações e servir de referência para comparação em outros estudos de caso.

\section{REFERENCIAS}

Almeida, C. P., Ramos, A. F., Silva, J. M. (2017), Sustainability Assessment of Building Rehabilitation Actions in Old Urban Centres, "Sustainable Cities and Society", n. 36.

Agopyan, V., John, V. M. (2011), O desafio da sustentabilidade na construção civil, v. 5, São Paulo, Blucher. 
Azevedo, S. L.; Rota, A.; Salvador, B. R.; Lamengo, F. (2008). "Levantamento e análise das manifestações patológicas no PAR regente (Pelotas/RS) e possíveis medida profiláticas” In: Encontro Nacional de Tecnologia do Ambiente Construído, 7, Fortaleza: ENTAC.

Batista, V. A. R. (2014), "Reabilitação sustentável: Análise integrada de edifícios habitacionais da alta de Coimbra", dissertação, Faculdade de Ciências e Tecnologias da Universidade de Coimbra.

Bourscheid, J. A., Souza, R. L. (2010), "Resíduos de construção e demolição como material alternativo", $1^{\mathrm{a}}$ ed., Florianópolis, IF-SC.

Brás, L. F. G. (2015), “Análise técnico-económica da reabilitação de edifícios antigos no âmbito das especialidades complementares de engenharia civil”, dissertação, Instituto Superior Técnico de Lisboa.

Brito, J. N. de S.; Formoso, C. T.; Echeveste, M. E. (2011), Análise de dados de reclamações em empreendimentos habitacionais de interesse social: estudo do Programa de Arrendamento Residencial, "Ambiente Construído", v. 11, n. 4, out./dez.

Bruntland, G. (1987), "Our common future”, Report of the World Commission on Environment and Development, Oxford University Press, Oxford.

Campelo, V.; Cavalcante, R. J. (2013), “Obras Públicas - A jurisprudência do TCU. $2^{a}$ ed.”, Belo Horizonte, Fórum.

Carraro, C. L.; Dias, J. F. (2014). Diretrizes para prevenção de manifestações patológicas em habitações de interesse social, "Ambiente Construído”, v. 14, n. 2, abr./jun.

Correia, G. de B. (2009), "Estudo de casos - Gestão de operações de reabilitação de edifícios antigos", dissertação, Faculdade de Engenharia da Universidade do Porto.

Cupertino, D.; Brandstetter, M. C. G. de O. (2015), Proposição de ferramenta de gestão pós-obra a partir dos registros de solicitação de assistência técnica, “Ambiente Construído”, v. 15, n. 4, out./dez.

Ioshimoto, E. (1988). "Incidência de manifestações patológicas em edificações habitacionais”. In: IPT, Tecnologia de edificações, São Paulo, Pini.

Jesus, C. R. M, de. (2008), "Análise de custos para reabilitação de edificios para habitação", dissertação, Escola Politécnica da Universidade de São Paulo.

Mateus, R. F. M. da S. (2009), "Avaliação da sustentabilidade da construção: Proposta para o desenvolvimento de edifícios mais sustentáveis", tese, Universidade do Minho.

Martins, D. M. (2011), "Estrutura geral de custos em obras de reabilitação de edificios em alvenaria de pedra existentes", dissertação, Instituto Politécnico de Viseu.

Miragaia, R. A. M. de A. (2011), "Cooperação de empresas em obras de reabilitação", dissertação, Faculdade de Engenharia da Universidade do Porto.

Mikhailova, I. (2004), Sustentabilidade: Evolução dos conceitos teóricos e os problemas da mensuração prática, "Revista Economia e Desenvolvimento", n. 16.

Possani, E. Demiliner, C. A. (2017), Desempenho, durabilidade e vida útil das edificações:

abordagem geral, "Revista Técnico-Cientifica do CREA-PR", Curitiba.

Qualharini, E. L. (2017), Evolução da reabilitação predial no século XXI, Gestão \& Gerenciamento, Rio de Janeiro, v. 1, n. 6.

Qualharini, E. L., Ducap, V. M. B., Oriolli, A. (2001). "Considerações sobre manutenção e reabilitação predial frente as questões de auto sustentabilidade" in: Congresso Nacional da Construção, Lisboa: APFAC (Portugal).

Rodríguez, A. D., Romacora, A. M., Vallejo, P. G., Sánchez, A. F., Marrero, M. (2017), Building rehabilitation versus demolition and new construction: Economic and environmental assessment, "Environmental Impact Assessment Review", n. 66.

Sáez, P. V., Merino, M. D. R., Porras-amores, C., Astorqui, J. S. C., Pericot, N. G. (2019), Analysis of best practices to prevent and manage the waste generated in building rehabilitation works. Sustainability, v. 11, n. 10.

Santos, H. de P.; Starling, C. M. D.; Andery, P. R. P. (2015), Um estudo sobre as causas de aumentos de custos e de prazos em obras de edificações públicas municipais, “Ambiente Construído”, v. 15, n. 4 , out./dez. 
Thomaz, E. (2001), "Tecnologia, gerenciamento e qualidade na construção", São Paulo, Pini. Thomsen, A.; Van, F. K. (2009), Replacement or renovation of dwellings: the relevance of a more sustainable approach, "Building Research e Information”, v. 37, n. 5-6.

Torgal, F. P., Jagali, S. (2010), “A sustentabilidade dos materiais de construção”, 2a ed., Guimarães, TecMinho.

Villa, S. B., Ornstein, S. W. (2013), “Qualidade Ambiental na habitação”, São Paulo, Oficina de Textos. 